\title{
Цифровизация в образовании
}

УДК 37.062.2

DOI: $10.14529 /$ ped210408

\section{ФОРСАЙТ-ЛАБОРАТОРИЯ В ФОРМИРОВАНИИ ПАРТИСИПАТИВНО-ЦИФРОВОЙ КУЛЬТУРЫ БУДУЩЕГО ПЕДАГОГА ГУМАНИТАРНОГО ПРОФИЛЯ (МЕЖДУНАРОДНЫЙ ОПЫТ)}

\author{
Э.К. Наурызбаева ${ }^{1}$, Н.В. Уварина ${ }^{2}$, В.В. Бежина ${ }^{1}$ \\ ${ }^{1}$ Костанайский региональный университет им. А. Байтурсынова, г. Костанай, \\ Республика Казахстан, \\ ${ }^{2} Ю$ Жно-Уральский государственный гуманитарно-педагогический университет, \\ г.Челябинск, Российская Федерация
}

\begin{abstract}
Данная статья посвящена обзору имеющихся форсайт-исследований в области образования, раскрытию основ разработки и целесообразности создания виртуальной форсайт-лаборатории гуманитарного профиля в Республике Казахстан. Задачи исследования включают обзор имеющихся исследований в области форсайт-технологий, анализ ситуации отношений стейкхолдеров к форсайт-исследованиям в образовании. Обзорноаналитическая часть исследования раскрывает особенности функционирования форсайтлабораторий стран дальнего и ближнего зарубежья преимущественно в техническом, экономическом аспектах и бизнес-профиле. Авторы приводят данные анонимного анкетирования и приходят к выводу о необходимости создания данного инструмента связи в системе профессионального образования гуманитарного цикла между субъектами микро-, мезо- и макросреды образовательного пространства для формирования партисипативноцифровой культуры будущего педагога. Предложенные направления открытой форсайтлаборатории рассматривают развитие метакомпетенций у студентов в гуманитарном профиле в процессе обучения, а дистанционный формат виртуальной форсайтлаборатории характеризуется с точки зрения мобильности и гибкости, что значительно удешевляет само исследование и аспекты внедрения полученных данных. Данное исследование является практико-ориентированным и находится на этапе моделирования обобщенного хаба в цифровом формате.

Ключевые слова: форсайт, форсайт-лаборатория, партисипация, партисипативноцифровая культура, виртуальная форсайт-лаборатория.
\end{abstract}

\section{Введение}

В современном образовании происходят системные изменения, касающиеся форм, содержания и целей взаимодействия субъектов образовательного процесса. Возможность предвосхитить варианты развития образования всегда интересовали многих представителей образования, науки, бизнеса. От заложенных компетенций специалистов зависит развитие будущего, поэтому использование кроссаспектного подхода к подготовке педагога позволяет прогнозировать формирование нового образовательного пространства.

Цифровая эпоха и неожиданный вызов перехода на дистанционное обучение во всех сферах образования Республики Казахстан предопределили сущность прогнозирования на основе форсайт-технологии. Понятие форсайта имеет различные трактовки, так как данная технология строится на принципах прогностичности моделирования возможной реальности, граничит с синергетикой и социологическими исследованиями бифуркаций и нелинейности развития.

Так, к примеру, в экономической теории форсайт является методом «долгосрочного планирования, ... используемый как системный инструмент формирования будущего и позволяющий учитывать возможные изменения во всех сферах деятельности» [1]. В области политических наук термин «форсайт» в современных исследованиях трактуется как «... систематический совместный процесс создания коллективного интеллекта о средне- 


\section{Цифровизация в образовании}

срочном и долгосрочном будущем» [20, с. 128], что подчеркивает партисипативный (совместно генерируемый) характер деятельности по планированию любого прогностического плана.

Интересна точка зрения относительно противопоставления понятий «инсайт» и «форсайт» в степени их вовлеченности в процесс планирования. Согласно мнению Э. Мастео и К. Доуви «форсайт не может быть рассмотрен вне связи с понятием «инсайт» в качестве совместного анализа ситуаций по типу «здесь и сейчас» [19].

Таким образом, в данном исследовании мы рассматриваем форсайт в качестве необходимого метода прогнозирования будущего образования на основе инсайта о совместной деятельности как субъектов образовательной деятельности, так и представителей мезо- и макросреды. Образ будущего образования отражен в дорожных картах развития образования Республики Казахстан, основан на единстве совместных долгосрочных планов как со стороны стейкхолдеров (работодателей, представителей культуры, бизнеса), так и со стороны участников образовательного процесса. К примеру, исходя из нормативного документа «Стратегический план Министерства образования и науки Республики Казахстан на 2020-2024 годы», понятно, что основная цель развития образования - это «развитие интеллектуального потенциала нации для вхождения в 30 наиболее развитых стран» [12].

Цель данного исследования - раскрыть особенность внедрения форсайт-лаборатории в учебном заведении как инструмента формирования партисипативно-цифровой культуры будущих учителей.

Задачи исследования:

1) представить обзор имеющихся исследований в области форсайт-лабораторий в гуманитарном профиле;

2) провести первичный сбор информации среди будущих учителей и стейкхолдеров на предмет наличия представления о форсайте в образовании;

3) определить перспективы исследования по созданию виртуальной форсайт-лаборатории гуманитарного профиля для развития партисипативно-цифровой культуры будущего учителя.

\section{Обзор литературы}

На различных уровнях теоретического обоснования исследуемой проблемы за основу были выделены исследования в области теории цифровизации и управления образова- нием И.В. Гайдамашко $[17,18]$, партисипации М.В. Смирновой (культурологически-партисипативный подход [11]), С.Л. Суворовой (партисипативное управление межкультурным образованием [14]), Н.С. Шкитиной (эмпатийно-партисипативная подготовка будущих учителей [16]); основы цифровизации в образовании Т.Е. Пахомовой (ИКТ-компетенции в цифровизации образования [10]), А.А. Строкова (ценностный аспект цифровизации образования [13]), Р.А. Шаухаловой (цифровая культура в информационно-образовательной среде вуза [15]).

Исследования в аспекте форсайта раскрыты в работах Г.А. Афанасьева (многоаспектное определение понятия «форсайт» [1]), А.С. Биккулова, М.С. Салазкина (международный анализ понятия «форсайт» [4]), М.В. Кнителя, П.А. Ларионова (форсайт-технологии в образовании [6]) др.

Но данные исследования в большей мере отражают преимущественно философский и экономический аспекты форсайта, отдельные его репрезентации и формы применения (технологии, методы, лаборатории).

Методы и результаты исследования

Современные исследования в области форсайт-технологии отражают преимущественно технологическое образование, экопространство, энергетику и социальные исследования, но в меньшей степени раскрывают образ будущего гуманитарного образования.

В данном исследовании мы понимаем необходимость раскрытия форсайт-технологии как образа будущего педагога, обладающего партисипативно-цифровой культурой именно в гуманитарной сфере.

Рассмотрим опыт применения форсайттехнологий в зарубежных странах.

Так, контент-анализ сайтов, содержащих ссылку на форсайт-лаборатории, дает определить следующее:

1. По частоте посещений и обращений к доменам лидирует Индия (https:// foresightlab.pk/), Российская Федерация (http://www.tutor-institute.com/srtinst/scilab/ forsitelabyakub/) и страны Америки.

2. В США имеется университет форсайта (Foresight University) - https://foresight.org, 3aнимающийся подготовкой форсайт-специалистов - консультантов в различных областях, в Российской Федерации - Сибирский институт будущего ([9]).

3 . В основном форсайт-технологии используются применительно к аналитике дан- 
ных и бизнес-технологиям (к примеру, https://www.fsight.ru/en/platform/).

Проведя сравнительно-сопоставительный анализ глобальных характеристик форсайтлабораторий (методом сплошной выборки), мы пришли к следующим выводам:

1. Большая часть форсайт-лабораторий построена на принципах синкретичной миссии и цели избранного аспекта исследования [7].

2. Форсайт-лаборатории преимущественно функционируют на базе институтов, университетов или иных исследовательских/образовательных организаций [2].

3. Направленность форсайт-лабораторий отражает преимущественно технические и экономические аспекты жизнедеятельности человека.

4. Особенность форсайт-лабораторий заключается в их прогностической направленности и гибкости.

Так, исходя из анализа международных форсайт-лабораторий, можем сделать вывод о преимущественно технической и экономической направленности данного рода инструментария.

В данном исследовании мы приводим спектр вопросов, необходимых для гипотетического утверждения о том, что форсайтлаборатория является необходимым звеном между субъектами микро-, мезо- и макросре$\partial b l$ в системе образования гуманитарного цикла в Республике Казахстан. Данный спектр вопросов включает следующие прогностические аспекты:

1. Каким образом осуществляется построение форсайт-лабораторий?

2. Как соотносятся целевые параметры различных форсайт-лабораторий стран СНГ и зарубежья?

3. В чем принципиальное различие между форсайт-лабораториями технического и гуманитарного цикла?

В нашем исследовании под партисипативно-цифровой культурой будущего педагога мы имеем в виду совокупность ценностных ориентаций, цифровых компетенций по совместному созданию, применению и анализу цифрового контента. Так, форсайт-технология может быть использована в качестве инструмента формирования исследуемой культуры будущего педагога гуманитарного профиля.

Применяя анализ результатов анонимного опроса, проведенного в цифровом формате среди учителей школ и колледжей, преподавателей вузов и стейкхолдеров - директоров школ, представителей бизнеса и культуры 236 человек, получили следующие данные:

1) $90 \%$ респондентов не имеют четкого представления о форсайт-исследованиях;

2) $78 \%$ ответов были направлены на то, чтобы иметь глобальный инструмент в виде форсайт-лаборатории в качестве обеспечения связи и преемственности между школой, вузом и макросредой;

3) $62 \%$ респондентов согласились с тем, что форсайт-лаборатория должна существовать в сфере гуманитарного знания в форме цифрового ресурса по типу «хаба».

На данном этапе исследования мы позиционируем виртуальную лабораторию как коммуникативный инструмент инновационной формы социального партнерства гуманитарного профессионального образования, представителей власти, местных сообществ и заказчиков образовательных услуг для прогнозирования востребованных метакомпетенций выпускника гуманитарного профиля на рынке труда и в новых сферах деятельности, стратегического видения будущих необходимых компетенций при разработке образовательных программ и определения эффективных путей их развития, с учетом потребностей всех заинтересованных сторон.

В рамках исследования планируется Создание архитектуры интерфейса виртуальной форсайт-лаборатории на основе программы «Форсайт. Аналитическая платформа» [8], возможности которой позволяют моделировать и прогнозировать с использованием встроенной библиотеки методов форсайта [5], подключения внешних пакетов и интеллектуального анализа, а также привлекать целевые аудитории (группы экспертов, стейкхолдеров) путем размещения объявления в социальных сетях [3], а также персональных приглашений потенциальным работодателям, элитарным представителям местных сообществ, представителям власти, ведущим ученым, представителям бизнеса.

\section{Выводы}

Таким образом, текущие результаты в техническом плане имеют следующие аспекты:

1) для разработки программного обеспечения используются серверная часть: РНРфреймворк Symfony, SQL база данных MariaDВД;

2) клиентская часть включает: JS-фрейм- 


\section{Цифровизация в образовании}

ворк VueJS, online-встречи, проведение форсайт-сессий на базе BigBlueButton;

3) программное обеспечение находится на стадии разработки: создан блок администрирования, в функции которого входят: разграничение прав доступа различных пользователей к информации; администрирование базы данных; осуществление идентификации и аутентификации пользователей; ограничение возможности работы с объектами в зависимости от статуса, присвоенного пользователю.

Создание виртуальной форсайт-лаборатории как коммуникативного инструмента инновационной формы социального партнерства гуманитарного профессионального образования и заказчиков образования, направленного на развитие метакомпетенций у студентов гуманитарного профиля, с учетом будущих профессионально-квалификационных изменений, диктуемых рынком труда, обогащает исследовательское поле, формирует базу для создания универсальных представлений о развитии метанавыков и метакомпетенций.

Несмотря на широкий спектр направлений форсайт-исследований в Казахстане, вопрос применения форсайт-технологии в области прогнозирования и развития метакомпетенций у студентов гуманитарного профиля в процессе формирования партсипативноцифровой компетенции остается нерешенным как в теоретическом, так и в практическом плане. Прежде всего это касается недостатка детальных методических подходов встраивания форсайта в рамки виртуальной лаборатории как коммуникативного инструмента социального партнёрства между гуманитарным образованием и трудовой сферой.

Таким образом, предложенные направления открытой форсайт-лаборатории (создание хаба работодателей, вовлечение в работу виртуальных сессий, построение карт будущего в плане метакомпетенций студентов гуманитарного профиля) рассматривают развитие метакомпетенций у студентов в гуманитарном профиле в процессе обучения, а дистанционный формат виртуальной форсайт-лаборатории более мобилен и практичен, что значительно удешевляет само исследование.

Данное исследование проводится в рамках грантового проекта «Виртуальная форсайтлаборатория как средство развития метакомпетенций в гуманитарном профиле» № AP09057871 договор № 100-КМУ2 от 18 марта 2021 года.

\section{Лumepamypa}

1. Афанасьев, Г.Э. Что такое форсайт? Попьтки определения / Г.Э. Афанасьев. Прогноз, 2020. - $11 \mathrm{c}$.

2. Бежина, В.В. Партисипативно-цифровая культура будущего педагога: возможности образовательной платформы Edmodo / В.В. Бежина, Н.В. Уварина // PrimoAspectu. 2021. - № 1 (45). - C. 80-85.

3. Бежсина, В.В. Формирование партисипативно-цифровой культуры молодежи: соииальное партнерство в VUCA-мире: моногр. I В.В. Бежина, Н.В. Уварина. - М.: Первое эконом. изд-во, 2021. - $176 \mathrm{c}$.

4. Биккулов, А.С. Форсайт в Канаде: два уровня / А.С. Биккулов, М.С. Салазкин // Форcaŭm. - 2007. - № 2 (2). - C. 2-5.

5. Волкова, И.А. Технология форсайтисследования в условиях иифровой экономики / И.А. Волкова, В.С. Петрова // Моск. эконом. журнал. - 2019. - № 1. - С. 260-267.

6. Книтель, М.В. Использование технологии «Форсайт» в прочессе обучения / М.В. Книтель, П.А. Ларионов // Наука и перспективы. - 2016. - № 1. С. 64-71.

7. Крюков, С.В. Форсайт: от прогноза $\kappa$ формированию будущего / С.В. Крюков // Пространство экономики. - 2010. - № 3 (2). C. 7-17.

8. Наурызбаева, Э.К. Foreseeing Foresight Laboratory - Kazakhstani participatory Experience in Creating humanitarian Hub / Э.К. Наурызбаева, В.В. Бежина // Вестник ЕНУ им. Л.Н. Гумилева. Сер. «Педагогика. Психология. Сочиология». - 2021. - № 4 (137). C. 43-48.

9. Открытая форсайт-лаборатория междисииплинарных исследований. - https:// myslide.ru/presentation/o-tkrytaya-forsajtlaboratoriya-mezhdisciplinarnyx-issledovanijmodul-1 (дата обращения: 15.11.2021).

10. Пахомова, Т.Е. Формирование ИКТкомпетентности студентов педагогического колледжа с учётом междисциплинарной интеграчии в условиях иифровизачии образования: автореф. дис. ... канд. пед. наук / Т.Е. Пахомова. - Улан-Удэ, 2020. - 25 с.

11. Смирнова, М.В. Развитие у студентов вузов культурь делового общения: дис. ... канд. пед. наук / М.В. Смирнова. - Челябинск, 2004. $193 c$.

12. Стратегический план Министерства образования и науки Республики Казахстан на 2020-2024 годbl. - https://science.kaznmu.kz/ 
wp-content/uploads/2015/06/strategicheskijplan-mon-rk-2020-2024.pdf (дата обращения: 15.11.2021).

13. Строков, А.А. Цифровая культура и иенности российского образования: дис ... канд. филос. наук / А.А. Строков. - Н. Новгород, 2021. $-165 \mathrm{c}$.

14. Суворова, С.Л. Партисипативное управление межкультурным образованием в вузе / С.Л. Суворова // Вестник ЮУрГУ. Сер. «Образование. Педагогические науки». - 2011. № 38 (255). - C. 26-30.

15. Шаухалова, Р.А. Педагогическая система формирования иифровой культуры студентов бакалавриата в информационнообразовательной среде университета: дис. ... канд. пед. наук / Р.А. Шахаулова. - Грозный, 2021. $-216 \mathrm{c}$.

16. Шкитина, Н.С. Культурно-исторические предпосылки становления и развития педагогической эмпатии как базовой харак- теристики эмпатийно-партисипативной подготовки будущего учителя / Н.С. Шкитина // Вестник Челяб. гос. пед. ун-та. - 2009. № 6. - C. 193-201.

17. Design of Educational Process from the Point of View of Management Humanitology / $V$. Terentyeva, E. Bushkanets, Yu. Karelina et al. // International Journal of Higher Education. 2020. - Vol. 9. - No. 34. - P. 34-36.

18. Influence of Poor Digital Competence on Procrastination of University Teachers / M. Kosycheva, T. Tuzhba, I. Gaydamashko, K. Esaulova // ICEMT 2020: The 4th International Conference on Education and Multimedia Technology. - 2020. - P. 73-77.

19. Mastio, E. Contextual insight as an antecedent to strategic foresight / E. Mastio, K. Dovey // Futures. - 2021. - Vol. 128. - P. 102715-102725.

20. Störmer, E. Science for Policy Handbook / E. Störmer, L. Bontoux, M. Krzysztofowicz et al. - Amsterdam: Elsevier, 2020. - P. 128-142.

Наурызбаева Эльмира Кенжегалиевна, кандидат исторических наук, ассоциированный профессор, ассоциированный профессор кафедры истории, Костанайский региональный университет им. А. Байтурсынова, г. Костанай, Казахстан, elmira_kn@mail.ru.

Уварина Наталья Викторовна, доктор педагогических наук, профессор, профессор кафедры подготовки педагогов профессионального обучения и предметных методик, Южно-Уральский государственный гуманитарно-педагогический университет, г. Челябинск, nuvarina@yandex.ru.

Бежина Виктория Валерьевна, ассоциированный профессор кафедры иностранных языков, Костанайский региональный университет им. А. Байтурсынова, г. Костанай, Казахстан, vukvuk85@mail.ru.

\title{
FORESIGHT LABORATORY TO FORM PARTICIPATIVE AND DIGITAL CULTURE OF FUTURE TEACHERS IN THE HUMANITIES (INTERNATIONAL EXPERIENCE)
}

\author{
E.K. Nauryzbayeva ${ }^{1}$, elmira_kn@mail.ru, \\ N.V. Uvarina2, nuvarina@yandex.ru, \\ V.V. Bezhina', vukvuk85@mail.ru \\ ${ }^{1}$ Kostanay Regional University named after A. Baitursynov, Kostanay, Republic of Kazakhstan, \\ ${ }^{2}$ South Ural State Humanitarian and Pedagogical University, Chelyabinsk, Russian Federation
}

The article provides a review on the foresight research in the field of education, determines the prerequisites of its development and claims the feasibility of creating a virtual foresight laboratory for the Humanities major in the Republic of Kazakhstan. The objectives of the research are to outline the foresight-technologies and to analyze the attitudes of stakeholders in education 


\section{Цифровизация в образовании}

towards foresight research. The review and analytical part of the study reveals the features of the functioning of foresight laboratories in the foreign countries, mainly in technical, economic and business profiles. The authors present the data of an anonymous survey and come to the conclusion that to form participatory digital culture of future teachers it is necessary to create this communication tool in the professional education system of the humanitarian cycle between the subjects of the micro-, meso- and macro- environment of the educational space. The proposed areas of the open foresight laboratory consider the development of meta-competencies among students of the humanities profile in the education process. The distance format of the virtual foresight laboratory is characterized in terms of mobility and flexibility, which significantly reduce the cost of the research and the implementation of the data obtained. This study is practiceoriented and is at the stage of modeling a generalized hub in a digital format.

Keywords: foresight, foresight laboratory, participation, participatory digital culture, virtual foresight laboratory.

\section{References}

1. Afanas'ev G.A. Chto takoe forsayt? Popytki opredeleniya [What is Foresight? Attempts to Define]. Prognoz, 2020. $11 \mathrm{p}$.

2. Bezhina V.V., Uvarina N.V. [Participative and Digital Culture of the Future teacher: the Possibilities of the Edmodio Educational Platform]. PrimoAspectu, 2021, no. 1 (45), pp. 80-85. (in Russ.)

3. Bezhina V.V., Uvarina N.V. Formirovanie partisipativno-tsifrovoy kul'tury molodezhy: sotsial'noe partnerstvo v VUCA-mire [Formation of Participatory Digital Culture of Youth: Social Partnership in the VUSA-World]. Moscow, Pervoe akademicheskoe izdatel'stvo Publ., 2021. 176 p.

4. Bikkulov A.S., Salazkin M.S. [Foresight in Canada: two levels]. Foresight, 2007, no. 2 (2), pp. 2-5. (in Russ.)

5. Volkova I.A., Petrova V.S. [Foresight Research Technology in the Digital Economy]. Moscow journal, 2019, no. 1, pp. 260-267. (in Russ.)

6. Knitel' M.V., Larionov P.A. [Using Foresight Technology in the Educational Process]. Nauka i perspektivy [Science and perspectives], 2016, no. 1, pp. 64-71. (in Russ.)

7. Kryukov S.V. [Foresight: from Predicting to Shaping the Future]. Prostranstvo ekonomiki [Economy space], 2010, no. 3 (2), pp. 7-17. (in Russ.)

8. Nauryzbaeva E.K., Bezhina V.V. Foreseeing Foresight Laboratory - Kazakhstani participatory Experience in Creating Humanitarian Hub. Bulliten of L.N. Gumilyov Eurasian National University. Pedagogy. Psychology. Sociology Series, 2021, no. 4 (137), pp. 43-48.

9. Otkrytaya forsayt-laboratoriya mezhdistsiplinarnykh issledovaniy [Open Foresight Laboratory for Interdisciplinary Research]. Availabale at: https://myslide.ru/presentation/o-tkrytaya-forsajt-laboratoriyamezhdisciplinarnyx-issledovanij-modul-1 (accessed 15.11.2021).

10. Pakhomova T.E. Formirovanie IKT-kompetentnosti studentov pedagogicheskogo kolledzha $s$ uchyotom mezhdistsiplinarnoy integratsii $v$ usloviyakh tsifrovizatsii obrazovaniya [Formation of ICT Competence of Pedagogical College Students Based on Interdisciplinary Integration in the Context of Digitalization of Education. Abstract of cand. diss.] Ulan-Ude, 2020. 25 p.

11. Smirnova M.V. Razvitie u studentov vuzov kul'tury delovogo obshcheniya. Diss. kand. ped. nauk [Development of a Culture of Business Communication Among University Students. Diss. kand. (Pedagogy)]. Chelyabinsk, 2004. 193 p.

12. Strategicheskiy plan Ministerstva obrazovaniya i nauki Respubliki Kazakhstan na 2020-2024 gody [Strategic plan of the Ministry of Education and Science of the Republic of Kazakhstan for 2020-2024]. Available at: https://science.kaznmu.kz/wp-content/uploads/2015/06/strategicheskij-planmon-rk-2020-2024.pdf (accessed 15.11.2021).

13. Strokov A.A. Tsifrovaya kul'tura i tsennosti rossiyskogo obrazovaniya. Diss. kand. philos. nauk [Digital Culture and Values of the Russian Education. Diss. kand. (Philosophy)]. Nizhny Novgorod, 2021. $165 \mathrm{p}$.

14. Suvorova S.L. Partisipativnoe upravlenie mezhkul'turnym obrazovaniem v vuze [Participatory Management of Intercultural Education at the University]. Bulletin of South Ural State University. Ser. Education. Pedagogy, 2011, no. 38 (255). pp. 26-30. (in Russ.) 
15. Shauhalova R.A. Pedagogicheskaya sistema formirovaniya tsifrovoy kul'tury studentov bakalavriata $v$ informatsionno-obrazovatel'noy srede universiteta. Diss. kand. ped. nauk [Pedagogical System for the Formation of Digital Culture of Undergraduate Students in the Information and Educational Environment of the University. Diss. kand. (Pedagogy)]. Groznyy, 2021. 216 p.

16. Shkitina N.S. [Cultural and Historical Prerequisites for the Formation and Development of Pedagogical Empathy as a Basic Characteristic of the Empathic and Participatory Training of the Future Teacher]. Vestnik Chelyabinskogo gosudarstvennogo pedagogichescogo universiteta [Bulletin of Chelyabinsk State Pedagogical University], 2009, no. 6, pp. 193-201. (in Russ.)

17. Terentyeva V., Bushkanets E., Karelina Yu., Karelina A., Gaidamashko I. Design of Educational Process from the Point of View of Management Humanitology. International Journal of Higher Education, 2020, vol. 9, no. 8 (34), pp. 34-36. DOI: 10.5430/ijhe.v9n8p34

18. Kosycheva M., Tuzhba T., Gaydamashko I., Esaulova K. Influence of Poor Digital Competence on Procrastination of University Teachers. ICEMT 2020: The 4th International Conference on Education and Multimedia Technology, NY, USA, 2020, pp. 73-77. DOI: 10.1145/3416797.3416832

19. Mastio E., Dovey K. Contextual insight as an antecedent to strategic foresight. Futures, Elsevir BV, 2021, vol. 128, pp. 102715-102715. DOI: 10.1016/j.futures.2021.102715

20. Störmer E., Bontoux L., Krzysztofowicz M., Florescu E., Bock A. Science for Policy Handbook. Amsterdam, Elsevier Publ., 2020, pp. 128-142. DOI: 10.1016/b978-0-12-822596-7.00012-7

Received 12 September 2021

\section{ОБРАЗЕЦ ЦИТИРОВАНИЯ}

Наурызбаева, Э.К. Форсайт-лаборатория в формировании партисипативно-цифровой культуры будущего педагога гуманитарного профиля (международный опыт) / Э.К. Наурызбаева, Н.В. Уварина, В.В. Бежина // Вестник ЮУрГУ. Серия «Образование. Педагогические науки». - 2021. - Т. 13, № 4. - C. 89-95. DOI: $10.14529 /$ ped 210408

\section{FOR CITATION}

Nauryzbayeva E.K., Uvarina N.V., Bezhina V.V. Foresight Laboratory to form Participative and Digital Culture of Future Teachers in the Humanities (International Experience). Bulletin of the South Ural State University. Ser. Education. Educational Sciences. 2021, vol. 13, no. 4, pp. 89-95. (in Russ.) DOI: $10.14529 /$ ped 210408 